\title{
From the Margin to the Center: The Transformation of the Identity Discourse of Chinese Ethnic Minority Literature
}

\author{
Xiaojun Gao \\ The College of Literature and Journalism of Sichuan University, Chengdu, China \\ Email: 1970217476@qq.com
}

How to cite this paper: Gao, X. J. (2018). From the Margin to the Center: The Transformation of the Identity Discourse of Chinese Ethnic Minority Literature. Advances in Literary Study, 6, 1-7. https://doi.org/10.4236/als.2018.61001

Received: October 21, 2017

Accepted: November 28, 2017

Published: December 1, 2017

Copyright $\odot 2018$ by author and Scientific Research Publishing Inc. This work is licensed under the Creative Commons Attribution International License (CC BY 4.0).

http://creativecommons.org/licenses/by/4.0/

\section{(c) (i) Open Access}

\begin{abstract}
Generally, the paper tries to rethink and rediscover the very notion and the identity discourse of Chinese ethnic literatures through multi-ethnic perspectives. According to the survey, the author finds ethnic minorities and their cultures are either under "ethnic erasure" or excluded from many of the orthodox Chinese national literary histories, while writers and artists of Han nationality have always taken the center stage. The misconception of Chinese literature as Han national literature is influenced by the orthodox Chinese national literary histories and hegemonic discourses. With the transformation of literary history from monistic to multivalent, Chinese ethnic minority literatures are moving from the margin to the center in the literary landscape of China, reclaiming their identities and providing another practical methods for Chinese literature to enter into a dialogue with the world from a new perspective.
\end{abstract}

\section{Keywords}

Ethnic Minority Literature, Literary Historiography, Han Chinese

Nationalism, Identity, Discursive Hegemony, Ethnicity

\section{Introduction}

Chinese ethnic minorities and their cultures are indispensable parts of the nation's history. However, a Han-centric perspective and discursive hegemonies in literary historiography have suppressed the practice of minority literatures, causing a partial conclusion that Han national literature represents Chinese literature. It is only recently, through the diligent works of many progressive Chinese scholars, that such a Han-centric perspective has started to yield ways for 
multivalent views of the past, and many scholars have raised questions about its inherent omission and suppression of ethnic minority literature. In point of fact, as the research moves along, when Chinese ethnic literatures and cultures enter into a wider global context, they represent "the center" for both the identity discourse and the nation's literature. It is the beginning for Chinese ethnic literatures to help create a new literary historiography that not only recognizes the contributions of ethnic works and their writers in the past but also embraces multilingualism and diverse textual practices for Chinese literature in times ahead.

\section{The Loss of Chinese Ethnic Literatures}

In ancient times, the theory of the monistic origin of the Chinese nation is the orthodoxy in Chinese national literary histories. Though China is constitutive of multi-ethnic groups, many literatures of Chinese ethnic literatures are excluded from Chinese literary historiography. From the research, the author finds several Chinese literary histories record literatures of ethnic minorities, for example, Wang Huazao's The Brief History of Contemporary Chinese Literature in 1985, Tan Weiping's The Course of Modern Chinese Literature in 2011 and Tang Tao's The History of Modern Chinese Literature in 1979 etc. Chinese scholar Xu Xinjian states that most printed forms of Chinese elite literatures and oral traditions even computer games or network writing in modern times are failed to reflect the integrated literary landscape of China (Xu, 2015).

Actually, the notion of "the grand unity" has already formed from two historical classics, for instance, The Commentary of Gongyang and The Spring and Autumn in Chinese history. Up to the Western Han Dynasty, a biographical literary works entitled the Historical Records has recorded issues about origin of nation, ethnic relations between the Hua-Xia (Han) nationality and non-Han nationalities. After that official histories of generations follow this pattern to compile ethnic minority biographies. In an authoritative historical works, The Twenty-Four Histories, historical facts about contributions of ethnic minorities for Chinese literature, the kinships between the Han nationality are all involved to strengthen the concept of "the grand unity" in historical works such as The Book of the Wei Dynasty, Book of the Northern Qi Dynasty, The History of the Liao Dynasty and The History of the Jin Dynasty.

Moreover, each boom in Chinese culture and thought is closely relates to conflicts and integrations between nationalities, such as prosperity of literature in the spring and autumn period accompanies with fierce wars. During the stormy era, border tribal communities enter into the center of plains to threaten the Han nationality, and the intricate residential pattern has formed. The second period of literary prosperity flourishes in the southern and northern dynasties which are highly praised by Chinese esthetics master Zong Baihua. At that time, ethnic minorities in the north as the Xianbei, the Di, the Qiang move towards south to capture the center. In the process of cultural integration, emerging 
many literary forms. For instance, the Yuefu Ballads in the north and south are different in contents and forms. Folksongs in the north ruled by non-Han nationalities are mainly about war, suffering, nomadic life and exotic landscapes, and distinguished for a kind of frank, powerful style, the Chile Song, Songs of the Mulan, the Qiyu and the Zi Liuma are as examples. On the contrary, in the south, folksongs are impressed with an emotional, delicate and lyric tone, for example, the Midnight Song, Songs of an Autumn Midnight, the Western Islet and the Qianxi. It is clear that Chinese ethnic minorities and their cultures not only play a crucial role in literary historiography, but also have a grand cultural treasure of Chinese history.

More remarkable, among studies of Chinese literary histories, a number of them are written in specific research. The Chinese Ethnic Minority Literature, for instance, compiled by Liang Tingwang and Huang Fengxian contains kinds of ethnic works and subjects including folk songs, folk poems, myths, legends, stories, singings, ethnical poetries, proses, fictions, dramas and films individually, and some provinces with many ethnic minorities as Yunnan, Sichuan, Guangxi, Qinghai publish their own literary histories of the Bai, the Naxi, the Tibetans, the Miao, the Yi, the Dai, and the Zhuang etc., they are also excluded from historical and literary writing. The loss of the identity discourse of ethnic minorities in the Chinese literary history violates the concept of "Han Chinese-Minorities Integration" and historical appearance of the nation. As to special histories of Chinese ethnic literatures labeled in "the Chinese literary history" are also the same as literary historiography which is restricted in a unilateral narration. Only when literatures of the Han nationality and ethnic literatures combine into one, can Chinese national literary histories and literatures be complete.

\section{The Chinese View of Literary History: From "Single" to "Polynary"}

Chinese scholar Cao Shunqing finds Chinese ethnic literatures are under a triple discursive hegemony of the west, the Han nationality and the elite class in China (Cao, 2005). By his account, as Chinese politics and economy travel on the road of westernization, western cultures and criticisms nearly overwhelm the discursive system of Chinese literature. Misled by the west-oriented pattern, Chinese literary theory begins to abandon their vernacular survival experience. Secondly, the discursive hegemony of the Han nationality influences the judgment for literatures of Chinese ethnic minorities, misguiding scholars to draw some partial conclusions such as "China has no epic". Thirdly, "the distinction of Yi (non-Han nationalities) and Xia (Han-Chinese)" and "the difference between the elegant and the popular" deprive of the rights and self-awareness of ethnic minorities. Ye Shuxian interprets the fixed thinking modes as "the effect of the spell" that caused by a literary orthodox of the Han Chinese majority and reinforced narration of official history by generations in our primary schools (Ye, 2009), while ethnic poet $\mathrm{Li}$ yuanxiaodi points out the fatal issue of ethnic literatures is about 
the discursive "dislocation" and "pillage", including "malposition" and "disguised displacement" in the second half of $20^{\text {th }}$ century ( $\mathrm{Li}, 2001$ ).

In my perspective, Chinese monistic history has caused the loss of literatures of Chinese ethnic minorities on the basis of "the distinction of Yi (non-Han nationalities) and Xia (Han-Chinese)" and "the difference between the highbrow and the lowbrow". If trace back to ancient times, we will find the Hua-Xia (Han) nationality locates in the center of geographic position and civilization, and from the period of spring and autumn, a distinct gap between the Han and non-Han nationalities has appeared influenced by the notion of "honoring the Hua-Xia (Han) nationality and excluding border tribal communities". At that time, Confucius also helps the Han nationality to consolidate status by advocating "the distinction of Yi (non-Han nationalities) and Xia (Han-Chinese)" in The Spring and Autumn Annuals. Up to the Qin Dynasty, geographical and cultural superiority further reinforce the status of the Han nationality, and Chinese ethnic minorities have to retreat back to the inferior position. Some of border tribal communities are compelled to move from the Yellow River, the rest of them accept cultures of the Han in the process of transforming the ethnic identity gradually. In the period of the Northern Wei Dynasty, Emperor Xiaowen initiates practical reforms of the Han nationality to encourage developments of the Xianbei in economy, culture, society, politics and power strength. Specific methods such as relocating the capital to Luoyang city in the name of "going to war towards the south", learning from their system, culture, clothing, language and customs are carried out to relieve national differences. In such a situation, the respect for the Han consolidates the view of Chinese monistic history.

Good news is that, recent years many scholars have raised questions about its inherent omission and suppression of ethnic minority literatures, and they put forward keywords including "Redrawing Chinese Literary Map", "Literarure of Sinophone", "Chinese New Literature" and "the Republic of Literature" (Wang, 2017). Since the concept of multi-ethnic literary history that was firstly verbalized by Chinese scholar Li Xiaofeng in 2006, heated discussions surround the exploration of feasible ways for multi-ethnic literatures to cross the border of culture, to reintegrate, and to be refocused have aroused public attention in Chinese academic circles. In other words, Chinese multi-ethnic literary history indicates the transformation of Chinese ethnic literatures and their identity discourse from the margin to the center. It is a new beginning for them to free from the suppression of discursive hegemonies and the centralization of the Han nationality.

\section{The Margin or the Center?}

Cambridge anthropology professor Alan MacFarlane believes that civilization is relative in the process of understanding diverse civilizations, and we can only get deep meanings through comparison (Xu, 2013). As Alan MacFarlane informs us to pay attention to the comparison of "the other", I think we should also notice 
certain questions. For instance, are Chinese ethnic minority literatures still on the margin of culture? If not, then how to embrace diverse textual practices for Chinese literary history under the guidance of the history of literature from a multi-ethnic perspective?

A few scholars remind us it is accessible to learn from western theorists who look into possibilities for mutual relations between space, right and culture in the $20^{\text {th }}$ century and to reflect on this issue. In this case, different from other living conditions of space, the margin turns into a social space where ethnic minorities inhabit. When we consider criticism of ethnic literatures from a marginal angle, a brighter outlook can be presented for us to reflect on the inner experiences in ethnic psychology and the construction of ethnic literary criticism (Ouyang, 2008). After looking into the impacts of post-colonial criticism on Chinese ethnic literatures since 1990s, other scholars prefer to set out to research in a more concrete context, predicting the status of Chinese ethnic literatures will have a great change. They will no longer exist as a subsidiary existence but a marginal existence relative to the mainstream literature in China. Therefore, difference, relationship, marginalization and confrontation become a basic view to understand literature of Chinese ethnic minorities (Yao, 2014).

As far as I'm concerned, the geographical position of Chinese ethnic minorities and their cultures seems conforms to the definition of the margin. The notion of the "margin" is usually defines as place of the boundary, symbolizing oppositions to the mainstream and the center. Geographically, Chinese ethnic minorities are on the periphery of the nation, while the Han nationality is at the heart of the continent. As the periphery of Chinese ethnic minorities has caused the margin of their identity discourse and literary pattern, the perspective seems reasonable. However, the relations between discourse and culture are quite complicated, not only a simple description of the center-periphery pattern. For marginal discourse and their cultures change accordingly when access to a variant discourse context. As the state-centered view from "the inside" to "the outside", our horizon should be broadened from a country, a nation to the world at last; the marginal position will become "the frontier" for ethnic literatures to communicate with the rest of the world. The awareness shifts outdated views that ethnic minorities from the southwest frontier must affiliate to mainstream literature to close to national literature, it also influences the transformation of the identity discourse of ethnic minority literature from periphery to the center of the literary landscape. In terms of Chinese ethnic literatures from the southwest frontier, there are plenty of development spaces and opportunities. In the early years of New China, writers in the Han nationality such as Xu Huaizhong, Peng Jingfeng, Bai Hua, Gong Liu, Zhou Liangpei create many classic and popular works the notable screenplay The Ashima, The Husband-Waiting Cloud, short story When Reed Pipes Begin to Play, and related film Love Song of Reed-Pipe etc. by using cultural resources with exotic elements like folklores, folk songs into literary creation. Not only that, the participation of ethnic writers and artists 
is also an important force for the construction of national history and literature. Deeply attached to ethnic cultures and languages, they provide new perspectives and inspirations for diverse textual practices and literary historiography. Nowadays, the ranks of Chinese ethnic minority writers and artists are continuously growing with a large number of splendid literary works. Social divisions caused by discourse power can be bridged and chords of society will play a beautiful melody by understanding differences and be sensitive to the margin (Ding \& Shen, 2013).

From academic significance, literatures of Chinese ethnic minorities have unique values and contributions, just as their developed folklores lay a solid foundation for the creation and development of national literatures. As many extraordinary pieces and writers with the global characters are likely to become a bright spot of world literature, it benefits for the recovery of literary history and the dialogue with the world. On the other hand, from practical social significance, under the guidance of multi-ethnic literary history, the identity discourse of Chinese ethnic minority literatures that change from the periphery to the center means the transformation of the status and the respect for their collective interests and cultures. The return of ethnic literatures has significance for the nation's long-term stability and harmonious relations.

\section{Conclusion}

Tracing back to the history, this article finds historical facts that Chinese ethnic minority literatures constitute a vital part of the nation's history and literary history, and the loss of them derives from the suppression of literary orthodox of historiography and discursive hegemonies in China. Only with the guidance of multi-ethnic literary history, can Chinese ethnic minority literatures and their cultures be free from discursive hegemonies of historiography to realize the transformation of their identity discourse from the periphery to the center. Effective approaches such as weakening binary opposition thoughts of literary history and focusing on global characters of ethnic literatures help to promote the prosperity of Chinese and ethnic literatures.

\section{References}

Cao, S. Q. (2005). The Studies of Chinese Ethnic Literature under a Triple Discursive Hegemony. Studies of Ethnic Literature, No. 3, 5-10.

Ding, J. X., \& Shen, W. J. (2013). Marginal Discourse Analysis: Some Basic Theoretical Issues. Foreign Languages and Their Teaching, No. 4, 17-21.

Li, Y. X. D. (2001). The Evaluation and Analysis for the Discursive Power of Contemporary Chinese Literature. Journal of Southwest University for Nationalities, No. 9, 85-88.

Ouyang, K. X. (2008). The Integration of Contemporary Ethnic Literature Criticism and the Posture of Criticism from the Margins. Contemporary Literary Criticism, No. 5, 57-60.

Wang, R. (2017). "Internal Structure": From Ethnic Literature to Multi-Ethnic Literature. Comparative Literature in China, No. 2, 143-157. 
$\mathrm{Xu}, \mathrm{X}$. J. (2013). Understanding Otherness' Civilization: the Cross-Cultural Dialogue between Different Ethnic Groups. Journal of Baise University, No. 4, 78-82.

$\mathrm{Xu}, \mathrm{X}$. J. (2015). Literature and Cultures in Multinational Country. Beijing: People's Publishing House, 3.

Yao, X. Y. (2014). Chinese Minority Literature: The Identity Discourse and Subjectivity Production. Jinan Journal, No. 2, 2-18.

Ye, S. X. (2009). The Construction of Chinese Literature and "Ethnic Literature": The Post-Modern Thinking from the Anthropology View. The Studies of Ethnic Literature, No. 2, 55-64. 